1. FCPS (Medicine),

FCPS (Cardiology)

Assistant Professor Cardiology

Faisalabad Institute of Cardiology,

Faisalabad.

2. MCPS (Medicine),

FCPS (Cardiology)

Assistant Professor Cardiology

Faisalabad Institute of Cardiology, Faisalabad.

3. MBBS

Medical Officer

Faisalabad Institute of Cardiology, Faisalabad.

4. FCPS (Cardiology)

Assistant Professor Cardiology

Faisalabad Institute of Cardiology, Faisalabad.

5. FCPS (Cardiology)

Assistant Professor Cardiology

Faisalabad Institute of Cardiology,

Faisalabad.

6. FCPS (Cardiology)

Assistant Professor Cardiology Faisalabad Institute of Cardiology,

Faisalabad.

Correspondence Address:

Dr. Muhammad Akram

Department of Cardiology

Faisalabad Institute of Cardiology,

Faisalabad.

mach167@hotmail.com

Article received on:

02/10/2019

Accepted for publication:

$25 / 12 / 2019$

\title{
FREQUENCY OF CORONARY ARTERY ANOMALIES IN PATIENTS UNDERGOING CORONARY ANGIOGRAPHY.
}

Imran Javaid ${ }^{1}$, Muhammad Akram², Shahbaz Amjad ${ }^{3}$, Rehan Riaz ${ }^{4}$, Ali Ehsan ${ }^{5}$, Ayesha Tariq ${ }^{6}$

ABSTRACT: Coronary artery anomalies are abnormalities in coronary arteries by birth (congenital) and involve their anatomy, course and function. They usually occur in association with other congenital cardiac defects. Coronary artery anomalies are usually clinically silent as they do not cause symptoms and are found incidentally but relatively few become evident by causing symptoms. Objectives: Determine the frequency of coronary artery anomalies in patients undergoing coronary angiography. Study Design: Cross sectional study. Setting: Faisalabad Institute of Cardiology, Faisalabad. Period: July to December 2017. Material \& Methods: Demographic information from all the patients was recorded and all of these individuals were undergone coronary angiography. All the collected data was analyzed by SPSS. Results: The mean age of the patients was $43.74 \pm 15.35$ years, male and female patients were equal in number. In this study coronary anomalies were present in 28(4.06\%) patients. Conclusion: Coronary artery anomalies are found quite frequently but usually are incidental finding.

Key words: $\quad$ Anomalies, Congenital, Coronary Artery, Heart, Patients.

Article Citation: Javaid I, Akram M, Amjad S, Riaz R, Ehsan A, Tariq A. Frequency of Coronary Artery Anomalies in patients undergoing Coronary Angiography. Professional Med J 2020; $27(2): 377-380$.

DOI: 10.29309/TPMJ/2020.27.2.4213

\section{INTRODUCTION}

Coronary artery anomalies are abnormalities in one or more of the cardiac coronary arteries by birth (congenital). They affect their anatomy (origin, course and termination) and function. The incidence of these anomalies is less than 1.5\% worldwide. These anomalies can be divided into benign or malignant, based on the symptoms they cause. Coronary anomalies are usually benign and common types are separate origins of left anterior descending (LAD) artery and left circumflex (LCX) artery from aortic left sinus of valsalva, LCX artery originating from aortic right sinus of Valsalva or right coronary artery (RCA) and RCA arising aberrantly from aorta. ${ }^{1}$

Coronary anomalies almost never cause symptoms and are most of the times diagnosed as an incidental finding during cardiac catheterization for other indications or at autopsy. Sometimes these anomalies cause symptoms due to arrhythmias, myocardial ischemia/ infarction, syncope and sudden cardiac death (SCD). ${ }^{2}$ These anomalies are the second most common cause of SCD in athletes, occurring between $12.2 \%$ and $17.2 \%$ in Western countries. ${ }^{3-5}$ In a study which was conducted in Peshawar, Pakistan, the coronary anomalies were seen in $2.2 \%$ of study population. In this study the commonest anomalies were myocardial bridging, separate origins of LAD and LCX from aorta and LCX artery arising from right side of aorta. ${ }^{6}$

The incidence of coronary anomalies in different groups of patients by various diagnostic tools and methods had been evaluated in several large studies. A higher incidence of coronary anomalies in young victims of SCD as compared to adults (4.15\% vs $1 \%$, respectively) had been reported in one study. ${ }^{7}$ Angelini et al. described an incidence of coronary anomalies in $5.6 \%$ of individuals using angiography. Split RCA (1.23\%) 
and RCA arising aberrantly near the right sinus of Valsalva (1.13\%) were the frequent anomalies. ${ }^{8}$

In a large retrospective study, the incidence of coronary anomalies was $1 \%$ in adults and $0.9 \%$ in children. The most frequent anomaly was aberrant origin of LCX in adults ( $25 \%$ cases). In symptomatic adults, the main causes were anomalous LCA from pulmonary artery and myocardial bridging. Anomalous LCA from the pulmonary artery was most common anomaly in children ( $48 \%$ cases) and most of the children were symptomatic. At autopsy, the incidence of coronary anomaly was $0.2 \%$. Coronary artery abnormalities were only second to hypertrophic cardiomyopathy as a cause of sudden cardiac death in young athletes. There was no race or sex predisposition. ${ }^{9}$ Coronary artery anomalies cause myocardial ischemia and manifest clinically as the following; myocardial dysfunction/heart failure, angina, syncope, arrhythmias and sudden cardiac death. ${ }^{10}$ In children, coronary artery anomalies usually presents in infancy and early childhood as cardiogenic shock, poor feeding or failure to thrive. They cause symptoms during activity in late childhood and adolescence. ${ }^{11}$

\section{OBJECTIVE}

To determine the frequency of coronary artery anomalies in patients undergoing coronary angiography.

\section{MATERIAL AND METHODS}

This study was Cross Sectional Study carried out in Faisalabad Institute of Cardiology, Faisalabad from July to December 2017. The sample size was calculated by using WHO formula;

Confidence Level: 95\%

Anticipated population proportion p: $2.2 \%$

Absolute precision required: $1.1 \%$

Sample size: 690 .

Consecutive sampling technique was used.

All patients of either gender between 18-70 years of age undergoing coronary angiography were included. Following cases were excluded from study; pregnancy, known serious allergic reaction to the contrast medium, renal and respiratory failure, patients who already had undergone cardiac catheterization procedure.

\section{Data Collection \& Analysis Procedure}

All eligible patients were enrolled in this study. Informed written consent was taken from all the patients and procedure was explained to them that this is a research based study. Their examination \& procedure were performed free of cost. Approval was taken from hospital ethical committee. All of these patients were subjected to coronary angiography. Demographic features and presence/absence \& types of coronary artery anomalies were recorded on proforma. All the data was entered and analyzed using statistical package for social sciences (SPSS). Mean and standard deviation was calculated for age of the patients. Frequencies with percentages were recorded for qualitative variables like gender, coronary anomalies/types of coronary anomalies. Chi square test was used for post stratification significance. A p-value of $<0.05$ was considered as significant.

\section{RESULTS}

In this study 690 patients were enrolled. The mean age of the patients was $43.74 \pm 15.35$ years (range 18 - 70 years). Male patients were $345(50 \%)$ and female patients were also $345(50 \%)$. Coronary anomalies were present in $28(4.1 \%)$ patients. Out of 28 patients, $13(46.43 \%)$ were male and $15(53.57 \%)$ were female patients. This difference was statistically insignificant $(p=0.70)$. \{Table-I\}

Among study population, myocardial bridging was found in $11(1.6 \%)$ patients, anomalies of origin of LCA, LAD \& LCX in $7(1 \%)$ patients, anomalies of origin of RCA in $7(1 \%)$ patients and coronary artery fistulae were found in $3(0.4 \%)$ patients. $\{$ Table-II $\}$

\begin{tabular}{|c|c|c|}
\hline \multicolumn{2}{|c|}{ Mean age (years) } & $43.74 \pm 15.35$ \\
\hline \multicolumn{2}{|l|}{ Male } & 345 (50\%) \\
\hline \multicolumn{2}{|l|}{ Female } & 345 (50\%) \\
\hline \multicolumn{2}{|c|}{ Coronary anomalies } & $28(4.1 \%)$ \\
\hline \multirow{2}{*}{$\begin{array}{l}\text { Coronary } \\
\text { anomalies } \\
\text { gender vise } \\
(n=28)\end{array}$} & Male patients & $13(46.43 \%) p=0.700$ \\
\hline & Female patients & $15(53.57 \%) p=0.700$ \\
\hline \multicolumn{3}{|c|}{$\begin{array}{l}\text { Table-I. Demographic features \& coronary anomalies } \\
\qquad(\mathrm{N}=690)\end{array}$} \\
\hline
\end{tabular}




\begin{tabular}{|l|r|}
\hline Myocardial bridging & $11(1.6 \%)$ \\
\hline Anomalies of origin of LCA, LAD \& LCX & $7(1.0 \%)$ \\
\hline Anomalies of origin of RCA & $7(1.0 \%)$ \\
\hline Coronary artery fistulae & $3(0.4 \%)$ \\
\hline Total & $28(4.1 \%)$ \\
\hline
\end{tabular}

Table-II. Frequency of types of coronary anomalies

\section{DISCUSSION}

Coronary artery anomalies have a wide range in terms of prevalence and age distribution depending upon study population and diagnostic method. In this study, mean age of the patients was 43.47 years (range $18-70$ years) and $50 \%$ were male. The frequency of coronary artery anomalies was $4.1 \%$ (28 cases out of 690 patients). Out of 28 patients, 13 (46.43\%) were male and 15 (53.57\%) were female patients. Myocardial bridging was found in $11(1.6 \%)$ patients, Anomalies of origin LMCA, LAD \& LCX were found in $7(1.0 \%)$, similar number of patients had anomalies of origin of RCA while $3(0.4 \%)$ patients had coronary artery fistulae.

Ibrahim et al described that in Peshawar prevalence of coronary anomalies were $2.2 \%$ and $61.12 \%$ patients were male. Myocardial bridging, separate origins of LAD \& LCX and LCX artery arising from right sinus of Valsalva were main anomalies. Most of the anomalies were benign $(95.7 \%)$ while $4.3 \%$ anomalies resulted in serious symptoms. ${ }^{6}$ The is no autopsy study in Pakistan describing coronary artery anomalies as cause of sudden cardiac death.

In a study by Yildiz et al revealed that incidence of coronary artery was $0.9 \%$ and mean age was $52 \pm 8$ years (range, 22-79 years) in 112 patients. Anomalous origin and course were more frequent $(89.3 \%)$ and coronary artery fistulae were present in $10.7 \%$ cases. $^{12}$ Namgung et al studied 8864 patients and described coronary anomalies in $103(1.16 \%)$ patients. Abnormal coronary origin and course were present in 90 patients $(87.4 \%)$ while in $13(12.6 \%)$ patients coronary artery fistulae were found. Among coronaries RCA was anomalous in 41 patients (39.8\%). ${ }^{13}$ Aybala Tongut and colleagues found anomalous coronary arteries in $9.37 \%$ study population with mean age of $55.9 \pm 12$ years. ${ }^{14}$

Schmitt $\mathrm{R}$ et $\mathrm{a}^{15}$ using computed tomographic coronary angiography (CTCA) studied 1758 patients and found anomalies coronaries in 44 $(2.5 \%)$ patients. Recently, Srinivasan et al. ${ }^{16}$ evaluated 1495 patients using CTCA described $0.8 \%$ prevalence of coronary anomalies.

As shown in different studies, coronary artery anomalies are found in middle aged adults during invasive and non invasive coronary diagnostic procedures or at autopsy. They have no sex predilection. They have wide variation in their prevalence but their types are quite similar. These anomalies are usually benign but in some patients they become symptomatic even life threatening.

\section{CONCLUSION}

Coronary artery anomalies are quite frequent and are found as incidental findings during coronary angiography or at autopsy. They are usually benign but could lead to life threatening symptoms or sudden death.

Copyright $\odot 25$ Dec, 2019.

\section{REFERENCES}

1. Khan HS, Iftikhar I, Kayani AM. Hyperdominant left anterior descending artery: A rare coronary artery anomaly. Journal of the College of Physicians and Surgeons-Pakistan: JCPSP 2016; 26(6 Suppl):S2-3.

2. Khetpal A, Khetpal N, Godil A, Ali MM, Lashari MN. Anomalous right coronary artery arising from left coronary cusp with coexisting valvular heart disease. The Journal of the Pakistan Medical Association 2016; 66(4):492-4.

3. Pursnani A, Jacobs JE, Saremi F, Levisman J, Makaryus AN, Capuñay C, et al. Coronary CTA assessment of coronary anomalies. Journal of cardiovascular computed tomography 2012; 6(1):48-59.

4. Nguyen A, Haas F, Evens J, Breur J. Sudden cardiac death after repair of anomalous origin of left coronary artery from right sinus of Valsalva with an interarterial course. Netherlands Heart Journal 2012; 20(11):463-71.

5. Raza K, Ali SN, Akhtar B. Frequency of coronary artery anomalies in patients of ischemic heart disease. JSZMC 2015; 6(3):849-52. 
6. Shah I, Faheem M, Hafizullah M. Frequency of coronary artery anomalies in adult cardiology practice; An angiographic study. Journal of Postgraduate Medical Institute (Peshawar-Pakistan) 2013; 27(2).

7. Basso C, Maron BJ, Corrado D, Thiene G. Clinical profile of congenital coronary artery anomalies with origin from the wrong aortic sinus leading to sudden death in young competitive athletes. Journal of the American College of Cardiology 2000; 35(6):1493-501.

8. Angelini P, Fairchild VD. Coronary artery anomalies: A comprehensive approach: Lippincott Williams \& Wilkins; 1999.

9. Tuo G, Marasini M, Brunelli C, Zannini L, Balbi $M$. Incidence and clinical relevance of primary congenital anomalies of the coronary arteries in children and adults. Cardiology in the Young 2013; 23(3):381-6.

10. Louis I Bezold. Coronary artery anomalies clinical presentation. 2015: http://emedicine.medscape.com/ article/895854-clinical.

11. Silva J, Costa M, Mota P, Leitão-Marques A. Myocardial infarction with anomalous coronary anatomy. Revistaportuguesa de cardiologia: orgaooficial da Sociedade Portuguesa de Cardiologia= Portuguese journal of cardiology: An official journal of the Portuguese Society of Cardiology 2009; 28(2):201-5.
12. Yildiz A, Okcun B, Peker T, Arslan C, Olcay A, Bulent Vatan $M$. Prevalence of coronary artery anomalies in 12,457 adult patients who underwent coronary angiography. Clinical cardiology 2010; 33(12).

13. Namgung J, Kim JA. The prevalence of coronary anomalies in a single center of Korea: Origination, course, and termination anomalies of aberrant coronary arteries detected by ECG-gated cardiac MDCT. BMC cardiovascular disorders 2014; 14(1):48.

14. Tongut A, Özyedek Z, Çerezci I, Erentürk S, Hatemi AC. Prevalence of congenital coronary artery anomalies as shown by multi-slice computed tomography coronary angiography: A single-centre study from Turkey. Journal of International Medical Research 2016; 44(6):1492505.

15. Schmitt R, Froehner S, Brunn J, Wagner M, Brunner $\mathrm{H}$, Cherevatyy $\mathrm{O}$, et al. Congenital anomalies of the coronary arteries: imaging with contrast-enhanced, multidetector computed tomography. European radiology $2005 ; 15(6): 1110-21$.

16. Srinivasan K, Gaikwad A, Kannan B, Ritesh K, Ushanandini K. Congenital coronary artery anomalies: Diagnosis with 64 slice multidetector row computed tomography coronary angiography: $\mathrm{A}$ single $\square$ centre study. Journal of medical imaging and radiation oncology 2008; 52(2):148-54.

\begin{tabular}{|l|l|l|l|}
\hline \multicolumn{3}{|c}{ AUTHORSHIP AND CONTRIBUTION DECLARATION } \\
\hline Sr. \# & \multicolumn{1}{|c|}{ Author(s) Full Name } & \multicolumn{1}{|c|}{ Contribution to the paper } & Author(s) Signature \\
\hline 1 & Imran Javaid & Data collection. \\
\hline 2 & Muhammad Akram & Writing. \\
\hline 3 & Shahbaz Amjad & Synopsis. \\
\hline 5 & Rehan Riaz & Proof reading / Editing. \\
\hline 6 & Ayesha Tariq & References.
\end{tabular}

